\title{
RAZMERJE MED POSEBNIM IN SPLOŠNIM V BEETHOVNOVIH KLAVIRSKIH SONATAH
}

\author{
Hellmut Federh of er (Mainz)
}

Za tistega, ki govori ob posebni priložnosti o Beethovnu, bi lahko sumili, da je hvalilec diktirane potrošnje, sentimentalnosti, zastarelih norm, skratka, da je zagovornik pozicij družbe blagostanja, ki so jih napredne sile že davno opustile. Ta sum se lahko stopnjuje do očitka, da je tradicija, če govorimo na splošno, v napoto sodobni glasbi, ker zavira pojavljanje novih slušnih orientacij. Ali se dá take argumente ovreči s protiargumenti? Obstaja opravičilo za tradicionalno kulti-viranje glasbe, ki presega historične, pedagoške in družbene reprezentativne namene? Do takšnega vprašanja nas sili današnja estetska situacija, ki je povsem nova, ker ni več zaključene glasbene kulture, na katero mislimo, kadar govorimo npr. o baroku, klasiki ali romantiki.

Zaključena glasbena kultura zahteva glasbeno govorico, ki je v nekem kulturnem krogu splošno obvezna. Podobno kot v gramatiki in sintaksi so tudi $\mathrm{v}$ glasbi sistemi, ki se ne porajajo iz ad hoc izmišljene konvencije, ampak so nastajali kot nekaj splošnega in objektivnega $\mathrm{v}$ teku večkrat dolgih obdobij skupno $\mathrm{s}$ tedanjo glasbo, njenimi zvrstmi in oblikami. Splošno je prisotno npr. kot oblikovalni tip $\mathrm{v}$ načelu vzorcev maquam arabskih, perzijskih in turških melodij ali kot modalnost $\mathrm{v}$ evropski glasbi srednjega veka. Podobno nastane $\mathrm{v}$ naprednejšem štadiju večglasja tonalnost, ki temelji na načelu kadenciranja in vključuje ritmično-metrične norme. Norme pa utemeljujejo glasbene nazore $\mathrm{z}$ ekskluzivnim značajem. ${ }^{1}$ Razmerje med po-

1 J.S. Bach označuje npr. generalbas kot "najpopolnejši fundament glasbe in tako naj bo enako kot glasba tudi generalbas konec in začetek vzroka in služi le v čast božjo in za okrepčilo duše. Kjer se tega ne upošteva, ni več prave glasbe, ampak le hudičevo dretje in lajnanje«. Philipp Spitta, John. Seb. Bach, zv. 2, Leipzig 1921, 915. Razširitev našega obzorja $\mathrm{s}$ spoznavanjem drugih glasbenih kultur, kar ima za posledico izgubo navidezne naivnosti Bacha, moramo plačati s preprosto in splošno znano resnico, da ne more danes nastati nobeno delo, ki bi bilo npr. na ravni Matevževega pasijona. 
sebnim, subjektivnim in splošnim, objektivnim določa muzikalni smisel in dovoljuje sodbo o kvaliteti in izvirnosti glasbe.

$\mathrm{Ni}$ dvoma, da je v današnji glasbi to razmerje omajano, bodisi da je posebno $\mathrm{v}$ celoti ali znatno absorbiralo splošno, kot $\mathrm{v}$ avantgardni glasbi, bodisi da je posebno zdrknilo pod splošno, kar se v marsičem dogaja v novi zabavni glasbi, ki se je izrodila v stereotipno praznino. Tisto nemoteno razmerje nam ni več spontano dano, čeprav ga - kot se zdi - ne moremo pogrešati, ne da bi bil umetniški instinkt zadovoljen. To pa opravičuje vprašanje, kako je pravzaprav s posebnim in splošnim. Morda lahko s tega vidika pojasnimo naš odnos do tradicije, o katerem se vprašujemo. če je za ta namen, ki zahteva preudarnost in objektivnost, posebno primerno Beethovnovo delo, je primerno zato, ker mu že od nekdaj niso oporekali izvirnosti. To se razodeva pri Beethovnu ne le $v$ tematski invenciji in motivičnem delu, ampak v najširšem smislu v slehernem oblikovalnem impulzu, ki ga daje posebno splošnemu. Tonaliteta in $\mathrm{z}$ njo povezana akcentna ritmika utelešujeta tisto splošno, ki stopa v ploden medsebojen odnos do posebnega, subjektivnega $v$ umetnini, s čemer se ta kot takšna tudi izkaže. Simbioza zajema vse plasti od najmanjšega muzikalnega smiselnega elementa do celotne oblike. Zato je splošno prav tako udeleženo pri oblikovanju motiva, téme, stavka in periode kot pri nastajanju tonskoprostornih zvez, ki rezultirajo iz enovitnosti vodenja glasov in harmonije. Te zveze pa so tiste, ki najbolj občutljivo reagirajo na napačno razmerje obeh kategorij. Tematsko motivične zveze in ustreznosti so še možne tudi pri izginevanju ali popolni odsotnosti tonalitete, tonskoprostorne pa ne. Slednje so najbolj gotov kriterij za sporazumevanje med splošnim in posebnim. Iz tega razloga naj posvetim predvsem pozornost temu problemu, ki so ga doslej pogosteje prezrli kot prepoznali.

Med najbolj znane klavirske sonate spada tako imenovana sonata "Les Adieux" op. 81 a, ki je nastala za časa Francozov v letih 1809 do 1810 in ima za program odhod in vrnitev Beethovnovega učenca nadvojvode Rudolfa, kateremu je tudi posvečena. Walter Riezler jo označuje kot edino res programsko Beethovnovo sonato, katere prvi stavek obvladuje simfonično v celoti začetni motiv "Zbogom" (»Lebewohl«) na pristno Beethovnov način. ${ }^{2}$ Že Hugo Riemann opaža, da "motiv očitno vlada ne le $\mathrm{v}$ svoji začetni podobi, ampak tudi v svoji inverziji ... in tudi z bolestnim udarcem navzgor poslednje note. ${ }^{3}$ Močna motivična koncentracija, ki je postala kasnejšim skladateljem edini vzor, je vsekakor očitna, vendar pa ta pri vsej preprostosti vodilnega motiva skoro ne pojasni, da bi bilo stalno ponavljanje posebno zanimivo. To postane zanimivo, šele, ko je vezano na tonskoprostorni

\footnotetext{
2 Riezler W., Beethoven, Zürich (6/1944), 88. 188.

3 Riemann H., Analyse von Beethovens Klaviersonaten III, Berlin 1919,
} 
red, ki se sicer poraja iz motivičnega elementa, a je sam več kot ta, ker je tudi $v$ njem obseženo splošno $v$ širokem smislu besede. Tako se tritonski vodilni motiv, ki se spušča postopoma od $\mathrm{g}^{1} \mathrm{na}^{\mathrm{es}}{ }^{1}$ in so mu podloženi zlogi »Le-be-wohl« ne ponavlja in variira na poljubni stopnji, ampak je povezan $\mathrm{v}$ ekspoziciji $\mathrm{s}$ stalnim izmenjavanjem med $\mathrm{g}$ in ges kot prvotnima krajnima tonoma. To nasprotje se dramatsko zaostruje od takta 35 dalje. Namesto stranske téme se pojavi tu vodilni motiv $\mathrm{v}$ basu $\mathrm{z}$ ges kot krajnim tonom, medtem ko prinese zgornji glas ta motiv v protipostopu, tako da doseže ges tudi omeneni glas, čeprav je zdaj motiv položen v dominantni tonski način. Posebno intenzivnost, ki jo ima krajni ton $\mathrm{g}^{3} \mathrm{v}$ taktu 48 , je pripisovati korekturi gesa $\mathrm{v} g$, ki izbrano visoko lego najbolje podpira. Vendar se ges še ne vda. V taktih $50-56$ oziroma $54-56$ se pojavi, ustrezno vstopu I. stopnje dominantnega tonovskega načina (B-dur), tritonski vodilni motiv sicer na kvinti $\left(\mathrm{d}^{2}-\mathrm{c}^{3}-\mathrm{b}^{2}\right.$ oziroma $\left.\mathrm{d}^{2}-\mathrm{c}^{2}-\mathrm{b}^{1}\right)$, medtem ko celinke odgovarjajo četrtinkam motiva $\mathrm{v}$ uvodu. Toda ges tudi tu nastopa vedno znova, čeprav ne več na eksponiranem mestu, ampak le v srednjih glasovih (takti 51, 55, 58, 60), in je stalno korigiran v g (takti 52, 56, 62, 64). Dramatsko nasprotje med $\mathrm{g}$ in ges, ki vlada $\mathrm{v}$ ekspoziciji Allegra, je že pripravljeno v počasnem uvodu tako, da njegov dodatek doseže $\mathrm{z}$ varljivim sklepom območje istoimenskega molovskega načina. S tem nastopi ges ${ }^{2}$ amesto $\mathrm{g}^{2}$ kot krajni ton $\mathrm{v}$ taktu 10, kar hkrati povzroči prestavitev $\mathbf{v}$ višjo dvočrtano oktavo, ges $^{2}$ je preklican $z g^{2}$ šele v 5. taktu (takt 21) Allegra, prav tam, kjer se spet pojavi tonika, medtem ko potek kompozicije od takta 12 naprej teži za zgornjo menjalno noto od $\mathrm{g}^{2}$, tj. za dominantno septimo $\mathrm{as}^{2}$, ki je konsonantno pripravljena s IV. stopnjo. ${ }^{4}$

Izpeljava, ki neposredno sledi, podvrže gosti motivični splet novi tonskoprostorni ideji, namreč horizontalizaciji dominantne septime $a^{2}{ }^{2} b^{1}$. Tonu as ${ }^{2}$, ki je dosežen kot na začetku Allegra, je dodan vodilni motiv tako, da se razvije $\mathrm{v}$ gornjem glasu postopoma padajoča melodična linija, ki seže do $b^{1}$ (Takt 88 ). Čim je dosežen $b^{1}$ in $s$ tem V. stopnja, se spet pojavi as ${ }^{2}$ kot glavni ton. ${ }^{5}$ Po njem se usmeri ostali del izpeljave. As gre navzdol iz dvočrtane oktave v enočrtano; to je igra lege, ki hkrati služi pomnožitvi vsebine. Od vodilnega motiva preostane nazadnje le prav ta ton, nakar sledi vzpon $\mathrm{k}$ reprizi; s tem pa je dosežen ponovno g v zgornjem glasu (takt 114).

Ta primer naj bi pokazal, da porodi motivika - naj bo ta uporabljena še tako koncentrirano kot $\mathrm{v}$ pravkar obravnavanem sonatnem stavku - tonsko prostorne zveze, ki so spojene s splošnim, ker imajo korenin€ $v$ tonaliteti. Učinkovitost jedrnih tonov je očitna, tonov, ki sicer predstavljajo motiviko, a niso $\mathrm{z}$ njo istovetni. če gledamo površno, se zdi, da zasidranost $\mathrm{v}$ tonskem prostoru skladatelja

${ }^{4}$ Schenker H., Der freie Satz, izdal in predelal Jonas O., Wien-ZürichLondon 2/1956, 156, 161 in dodatek, figura 119, 7; 124,4.

5 Ib., 107 in dodatek figura $62,4$. 
veže, v resnici pa mu dovoljuje, da doseže sicer nedosegljivo bogastvo strukturnih zvez. ${ }^{6}$

Jedrni toni razodevajo idejo ogrodnega stavka. Ta ideja teži za zvočno uresničitvijo. Za primerjavo jo lahko demonstriramo na načelu variacije, ki je možna le, ker se za njeno zunanjo pojavo skriva téma. Ta predstavlja sistem tonskih in zvočnih zvez, katerim se podrejajo tiste, ki nastopijo $\mathrm{v}$ variacijah. Variacija pa nadalje ponazarja načelo pridobivanja tonskega prostora. Prav ta oblika mora izčrpati vsa sredstva kontrasta, če hočemo, da vrsta variacij ne utruja, ampak pokaže témo stalno v novi osvetlitvi. $\mathrm{Za}$ to daje menjava leg in razširitev tonskega prostora odlično možnost. Zaključek sonate op. 109, ki je oblikovan kot variacijski stavek, pokaže npr. v zadnji variaciji takšno tonskoprostorno razširitev, ki se povrne nazadnje spet na nevariirano témo izhodišča. Zvočnobarvno lesketanje, ki ga povzroči trilček deloma obeh rok, je mestoma tako močno, da se zdi spoznavna zvezna linija $\mathrm{z}$ avantgardnimi tvobrami, npr. $\mathrm{z}$ »Atmosphères« G. Ligetija, kjer je razširjanje in krčenje zvočnih ploskev prav tako konstitutivno. Zveza je tu seveda zunanja. Pri Beethovnu nastopa barva kot akcidens, pri Ligetiju pa se osvobodi tonskega prostora, ki utone $\mathrm{v}$ šumu in mešanici zvokov, ne da bi bil zaznaven $\mathrm{v}$ redu zvočnih zgostitev in razredčitev ter njihovih različnih mešanic nov sistem, $\mathrm{s}$ čemer bi se edino dalo rešiti splošno. Tu preostane le posebno. Posebno pa samo zase ne dá nobene izvirnosti, temveč se približuje samovoljnosti in naključju ali pa je s tem identično. Kako zelo nasprotno izvirnost omogoča povezavo posebnega s splošnim, dokazujejo klavirske sonate Beethovna, od katerih ima vsaka svoje posebno obličje. Tu pomaga način oblikovanja, ki zlasti odlikuje sonatno obliko v ožjem smislu kot vodilno formo klasike, namreč povezovanje pesemskega elementa $\mathrm{z}$ improvizacijo. Beethovnove klavirske sonate so klasične ne nazadnje zato, ker sta si obe načeli $\mathrm{v}$ ravnotežju.

Posebno učinkovito povezavo pesemskega in improvizacijskega elementa kaže npr. prvi stavek omenjene sonate op. 109. Prva misel je oblikovana pesemsko, izlije pa se v varljivi sklep - označen je z novim tempom -, ki uvaja improvizacijsko zasnovani del. Namen varljivega sklepa je, da prepreči nastop pričakovane dominante, ki bi bil tu v smislu sonatne oblike dosti prezgoden. Kot harmonsko presenečenje pripravlja hkrati sledeči improvizacijski pasus, ki vsebuje drugo misel in razpade $\mathrm{v}$ dva dela (takti 9-11, 12-15). Kar je predvsem nenavadno, je stroga tonskoprostorska vezanost in to kljub

6 Tako se začenja npr. prvi stavek Waldsteinske sonate op. $53 \mathrm{~s}$ štiritaktno mislijo. Njena ponovitev na naslednji nižji stopnji se vključuje $\mathrm{v}$ vodenje glasov, ki gre navzdol kromatično od tonike c do dominante g in ustvari enovitost začetka stavka. Podobno je oblikovan začetek stavka Adagio molto iste sonate. Prim. Jonas O., Das Wesen des musikalischen Kunstwerks, Wien 1934, 172; Federhofer H., Die Funktionstheorie H. Riemanns und die Schichtenlehre H.Schenkers, Bericht über den Internationalen musikwissenschaftlicen Kongress Wien, Mozartjahr 1956, izdal E. Schenk, Graz-Köln 1958, 186. 
improvizacijski svobodi. ${ }^{7}$ Osnova prvemu delu, ki se končuje s polsklepom v H-duru, je od $\mathrm{a}^{2}$ do cis $^{2}$ postopoma padajoča linija zgornjega glasu. Drugi del se sicer poslužuje novih diminucij, opisuje pa pravzaprav isti le za oktave navzgor in navzdol razširjeni tonski prostor. Pri tem se vrine v postopnem spuščanju zgornjega glasu, ki poteka prav tako od $a^{2}$ navzdol, med gis in fis ton fisis, kar omogoča v taktu 13 vstop Dis-dura, ki je voden kromatsko dalje do sekstakorda V. stopnje. Navidezno nameravana modulacija v Gis-dur je $s$ tem .ovržena in na začetku takta 14 imamo le oktavno razširjeno pozicijo takta 11 , tako da se razkrije kromatična zgostitev od $\mathrm{g}^{2}$-gis ${ }^{2}$ fis $^{2}$ (takti 9-11) v a ${ }^{2}$-gis $^{2}$-fisis²-fis ${ }^{2}$ (takti 12-14) primarno ne kot zvočnobarvna, ritmično intenzivirana varianta, kar sekundarno tudi je, ampak kot fenomen glasov, ki služi korespondiranju prvega in drugega stavka. Medtem ko konča prvi stavek s polsklepom, vzpostavi šele drugi, ki prvega glede tonskega prostora posnema, popolni sklep v svoji končni tonaliteti. Šele v taktu 15 nastopi dotlej prihranjena V. stopnja (H-dur) v tisti poziciji - namreč $\mathrm{s} \mathrm{h}^{2} \mathrm{v}$ zgornjem in $\mathrm{H}^{1} \mathrm{v}$ spodnjem glasu —, ki bi jo pričakovali že v 9. taktu, a jo tam varljivi sklep preprečil. Za ponazoritev naj služi tale skica tonskega prostora:

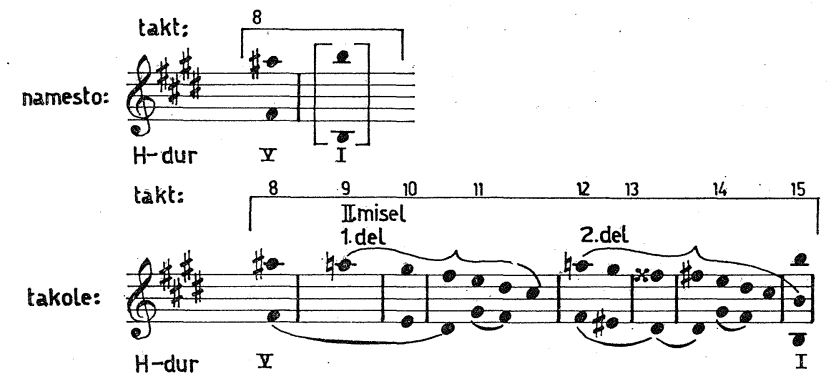

Sekunda ais $\mathrm{s}^{2} \mathrm{~h}^{2}$ je spremenjena v septimo ais $\mathrm{s}^{2} \mathrm{~h}^{1}$. Da pa se vendarle pojavi tudi $h^{2} \mathrm{v}$ taktu $15, \mathrm{~s}$ čimer je skladatelj ustregel nasprotju lege, je pripisovati premiku zgornjega glasu za oktavo navzgor vse od takta 12 dalje. Wilhelm Furtwängler, edinstveni interpret Beethovnove glasbe, govori o daljinski zvezi, ki odlikuje klasično mojstrovino, in o poslušanju iz daljave, ki ga zahteva ${ }^{8}$. Tu imamo vzorni primer za to, kako oboje učinkuje.

7 Beethoven-Schenker, Erläuterungs-Ausgabe der letzten fünf Sonaten, sonata v E-duru op. 109,26 in dalje. Schenker H., ib., 123, dodatek, figura 89,$1 ; 117,2$. Avtograf te sonate je ponovno izšel $\mathrm{v}$ faksimilu s predgovorom O. Jonasa. Izdala ga je The Robert Owen Lehman Foundation, New York City/65.

${ }^{8}$ Furtwängler W., H. Schenker, ein zeitgemässes Problem v publikáciji Ton und Wort istega avtorja, Wiesbaden 1954, 201 in dalje. 
Izpeljavo, ki sledi, obvladuje motivično povsem začetni del, katerega gradivo je še docela neizrabljeno. Neprekinjeno stopnjevanje - povezano $\mathrm{s}$ tonskoprostorsko ekspanzijo - vodi na dinamičnem višku $\mathrm{k}$ reprizi, $\mathrm{ki}$ je $\mathrm{v}$ primerjavi $\mathrm{z}$ ekspozicijo $\mathrm{v}$ marsičem spremenjena. Je bogatejša zaradi pridobljenega izkustva $\mathrm{v}$ izpeljavi in tudi improvizatorsko oblikovani pasus je spremenjen, čeprav je po tonskoprostorski ideji $\mathrm{z}$ ekspozicijo zelo soroden. ${ }^{9}$

Če se začenja ta sonata $\mathrm{s}$ pesemsko mislijo, ki jo podobno kot $\mathrm{v}$ prvem stavku sonate op. 110 zamenja improvizatorska misel, pa lahko nasprotno označujemo začetek sonate op. 31 št. 2 kot notirano improvizacijo, iz katere se téma šele razvije. Značilen je tako rekoč v smislu preludija navrženi arpedžirani sekstakord A-durovega trizvoka, čigar sekstni prostor cis-a je šele postopoma izpolnjen v naslednjih taktih Allegra $\mathrm{z}$ vključitvijo zgornje menjalne note $\mathrm{b}$ v spodnjem glasu. Cis kot najgloblji ton arpeggia stopi $\mathrm{v}$ zvezo $\mathrm{z}$ basovsko noto $\mathrm{E} \mathrm{v}$ taktu 7 , nad katero se pojavi sekstakord C-durovega trizvoka. To je evidentno iz analognega oblikovanja obeh taktov Larga. Neposredno zatem koraka e v mali oktavi postopoma kromatično prek f-fis-g-gis dalje $\mathrm{k}$ a kot naslednjemu končnemu tonu basa, nad katerim se pojavi kvartsekstakord I. stopnje d-mola. Višek napetosti, ki jo doživljamo sedem in pol taktov, je zdaj dosežen, pri čemer je končno priveden kvartsekstakord po padajoči diminuciji v prostor velike oktave. Razvez je v drugi polovici takta 20 , v taktu 21 pa se pojavi tonika $\mathrm{z}$ osnovnim tonom $\mathrm{D}$ v veliki oktavi. Lahko bi si predstavljali, da se sonata začenja šele na tem mestu $\mathrm{z}$ ostro in energično témo $\mathrm{v}$ basu. To bi bilo glede na detajl tudi možno in je izvedeno $\mathrm{v}$ reprizi, kjer se del, ki sedaj sledi (takti $21-40$ ), sploh več ne pojavi, medtem ko je improvizatorski uvod tokrat skrbno izoblikovan in - razširjen od 20 na 28 taktov - vodi neposredno v drugo misel. Zato je moral Beethoven izkazati prav temu uvodu posebno pozornost, tako da se postavlja vprašnje o njegovi funkciji. Harmonsko ogrodje uvoda se opira na basovske tone Cis (takt 1) - E (takt 7) - A (takt 17), ki skupaj utelešujejo prav tisti sekstakord A-durovega trizvoka, ki kot arpeggio $\mathrm{v}$ prvem taktu začenja sonato. Toda istočasno se iz ideje lomljenja zvokov Cis-E-A porodi tudi téma D-F-A-d, ki nastopi v taktu 21. Ta je sama po sebi tako preprosta, da bi jo lahko skupno $\mathrm{z}$ njenim nadaljevanjem v zgornjem glasu (izpisano obigravanje kvintnega tona a $\mathrm{s}$ pomočjo spodnje in zgornje menjalne note) prisodili vsakemu skladatelju Beethovnovega časa. Svojo zvišenost dobi šele iz konteksta kot konsekvence lomljenja zvokov Cis-E-A in figure dvojnega priložka (takt 6 Adagia), ki ga imitira zgornji glas $\mathrm{v}$ taktih 22-24.

$\mathrm{V}$ reprizi podčrtavajo improvizacijski značaj uvoda recitativne interpolacije, ki jih natančneje opiše oznaka »con espressione e semplice«. Harmonično ogrodje se opira kot v ekspoziciji na basovske tone cis (takt 143) - e (takt 153) - a (takt 171), ki dajo skupaj horizontalno razstavljen sekstakord V. stopnje. Najpomembnejšo spre-

${ }^{9}$ Beethoven-Schenker, Erläuterungsausgabe der letzten fünf Sonaten, 31 in dalje. 
membo doživi pot od 2 . k 3. basovskemu tonu, namreč od e $\mathrm{k}$ a. To pot premeri skladatelj sícer tako kot $\mathrm{v}$ ekspoziciji, tj. kromatično in postopoma navzgor, vendar jo izpolni z drugimi prehajalnimi akordi, za kar da spodbudo enharmonična zamenjava $\mathrm{f} v$ eis $\mathrm{v}$ taktih 158 do 159. Nadalje nastopi že tam, kjer je dosežen $\mathrm{v}$ basu končni ton a (takt 171), druga misel. Da se Beethoven odpoveduje v reprizi prvi misli, ki je praktično izpolnila izpeljavo in je zato že močno izrabljena, je jasno v celoti šele iz pomena improvizacijskega dela.

To pa spet obrača pozornost na razmerje med improvizacijo in témo v ekspoziciji. Med obema vlada tonskoprostorski odnos, ki ga sicer sproži poseben domislek, a suponira tonaliteto kot splošno. Če omejimo splošno na funkcionalno harmoniko in povezovanje vseh zvokov z osrednjo toniko, bi se lahko zdelo, da je povzročila izguba splošnega, do katere je ta čas dejansko že prišlo, le stilno spremembo, kakršne so bile številne prejšnje. Če pa priznamo, da je odvisen od njegove eksistence tudi celoten tonskoprostorski sklad, ki vključuje vodenje glasov, moramo tolmačiti njegovo izgubo, ki spodreže same korenine, kot žrtvovanje muzikalne oblike. Zato je poskus Paula Hindemitha, da reši splošno za novo glasbo, razumljiv. Vendar je tu gotovo upravičena kritika Theodora W. Adorna, da splošno ne more biti stvaritev posameznika. ${ }^{10}$ Arnold Schönberg je poskušal nadomestiti splošno z dvanajsttonsko tehniko, ki je že postala historična. Adorno je to iluzijo zgodaj prepoznal, čeprav je, kot je mislil dialektično, hkrati zagovarjal Schönberga. Že leta 1940/41 piše: »Tako je v Schönbergovih rondojih praksa, da skladatelj prinese pri vsakem nastopu rondoja v ritmu téme novo melodično serijo, s čimer doseže učinek, ki je podoben variacijam... Dojeti pa se vsekakor ne dá nič več kot to, da so intervali k ritmu téme drugačni, kot so bili prvič; nekega smisla se iz melodične modifikacije ne dá več slišati ... Najbolj nevaren pri tem je tisti način melodične približnosti, ki sicer ohranja obrise stare melodije - torej postavi ustrezno velikemu ali majhnemu skoku na analognem ritmičnem mestu tudi prav takšnega - toda le v kategorijah kot sta velik in majhen, ne da bi bilo pri tem vsaj malo važno, ali je karakteristični skok velika nona ali decima. «11 $\mathrm{S}$ temi besedami je nedvomljivo izražena izguba tonskega prostora in tonskoprostorskih odnosov $\mathrm{z}$ zakrnitvijo vsega splošnega. $\mathrm{V}$ istem smislu pravi tudi Rudolph Stephan, ki spada v ožji Adornov krog, naslednje: »V novi glasbi posebno žre splošno. Zato se dá najenostavneje prikazati zgodovino nove glasbe kot zgodovino razpada tradicionalne glasbene govorice $; ;^{12}$ ta glasba je privedla do tega, da so komponisti danes "praznih rok«. ${ }^{13}$ Uporabljali so in še uporabljajo številne nove

${ }^{10}$ Adorno Th. W., Ad vocem Hindemith v Adorno Th. W., Impromptus, Frankfurt 1968, 70 in dalje.

11 Morthenson J.W., Nonfigurative Musik, predgovor: Metzger H. K., Stockholm 1966, 11.

12 Stephan R., Das Neue der Neuen Musik v Das musikalisch Neue und die Neue Musik, izdal Reinecke H. P., Mainz 1969, 50.

13 ib., 63. 
rede; vsi ti pa imajo tako kot že dvanajsttonska tehnika A. Schönberga in njegove šole značaj posebnega. Njihovo naglo izmenjavanje jih razkrinkuje kot modno pogojene. Heinz-Klaus Metzger, zagovornik »nefigurativne glasbe " govori naravnost o »brezupni serializaciji vseh parametrov zvočnega fenomena«. ${ }^{14}$ Vsekakor si skuša poslušalec celo tam, kjer mu dozdevno zveni kaos, še vedno ustvariti nek red, pa naj bo ta še tako boren. „Cageov učenec Christian Wolff je kmalu izrazil pomembno izkustvo, ko je dejal, da se bo, pa naj se v kompozicijsko tehničnem pogledu še tako prizadevamo za porušenjem muzikalne zveze, čez nekaj časa iz vsega tega vendarle pojavila melodija.« ${ }^{15}$ Tisto, kar označuje Nicolai Hartmann kot »umetniški čudež skladbe, ko se ustvari sredi njenega časovnega zaporedja enovitost celotne tvorbe in se ta sukcesivno napolni, zaokroži in strne v zgradbo «, 16 išče in obupno poskuša poslušalec še celo tam, kjer se tega komponist ( v kolikor še zasluži to ime!) zavestno izogiba. Ali se dá v takih okoliščinah estetsko uresničiti tudi le $\mathrm{v}$ najbolj skromnih mejah materialno miselnost namesto dosedanjega oblikovalnega mišljenja, ki mu lahko sledimo nazaj vse skozi tisočletja, je zelo dvomljivo. Obstaja sum, da ostanemo v skrajnem primeru pri grobem akustičnem dejstvu, ki ne vodi niti $\mathrm{k}$ razširitvi zavesti niti $\mathrm{h}$ kreativnemu procesu, ampak da lahko vsak producira kot pač hoče. Pred tem pa ne varuje niti bogokletna prevzetnost kretenj obupa in absurdnega niti provokatorsko negriranje. Oboje $\mathrm{v}$ osnovi le zasmehuje človeka ne da bi mu pomagalo.

Znani dirigent Leonhard Bernstein je dejal nekoč $\mathrm{v}$ intervjuju s "Spieglom", da so najboljši umetniški dosežki Schönberga, Antona Weberna in Albana Berga tam, kjer najmočneje udarja na dan hrepenenje po izgubljeni tonalnosti. Neprestano je bil naziranja, da je smisel za tonalnost že v človeka vgrajen. ${ }^{17} \mathrm{Zdi}$ se, da mu daje glasbena zgodovina prav. Izguba splošnega je $\mathrm{v}$ našem času sicer nesporno in očitno pogojena po tem, da smo $\mathrm{v}$ eri tehnike in manipulacije $\mathrm{v}$ marsičem zavrgli in pokopali duševne sile, medtem ko je hrepenenje za splošnim živo in morda iz navedenih razlogov še močneje kot kadarkoli poprej. Na tem pa temelji upanje tradicije. Ta lahko dá človeku, kar mu sedanjost pridržuje in mora pridrževati kot zgodovinsko pogojena usoda. In zato se Beethovnu ne moremo odpovedati. $\mathrm{V}$ njegovi glasbi iščemo in odkrivamo tisto, kar potrebujemo, a v sedanjosti več ne najdemo oziroma premalo najdemo. In v tem je globlji smisel Beethovnove umetnosti v našem času.

${ }_{14}$ Morthenson J. W., Nonfigurative Musik, 9.

15 Mortherson J. W., ib., 7.

16 Hartman N., Ästhetik, Berlin 1953, 119.

17 Das Orchester 15, 1967, 117. 


\section{SUMMARY}

The present aesthetic situation is completely new because a self-contained musical culture, which we think of when we speak about Baroque, Classicism or Romanticism, no longer exists. Hence the question arises of the justification of the traditional cultivation of music which goes beyond historical, educational and socially representative aims. A self-contained musical culture requires a musical idiom which possesses a general fixed framework for a particular culture. Just as in grammer and syntax, there are musical systems which do not spring from any ad hoc devised convention but which arise as something general, and objective in the course of longer periods of time together with the music of the period, its types and forms. The general element is present, for instance, as types in the Maquam principle of Arabic, Persian and Turkish melodies or as modality in European mediaeval music. In a similar way, tonality, based on a principle of cadences, which implies rhythmic-metrical norms, arises in an advanced phase of polyphony. Musical ideologies with an exclusive character are founded by normes. The relationship of the particular and subjective to the general and objective qualifies the musical sense and permits us to judge the quality and originality of the music. There is no doubt that this relationship has been upset in present-day music, be it that the general has been completely or mostly absorbed by the particular, such as in avant-garde music which no longer recognizes a tonal language, or be it that the particular has fallen behind the general, such as in many parts of modern popular and light music which is degenerating into empty formulae. We no longer spontaneously receive this undisturbed relationship, although - as it seems - we cannot miss it without leaving the artistic instinct unsatisfied. This justifies the question of the particular and general. If Beethoven's work is especially appropriate for an undertaking which demands insight and objectivity, then this is because his originality has never been disputed. This is evident in Beethoven not only in his thematic invention and motivic work, but, in the widest sense, in every impuls of creation which the general receives from the particular. Tonality and the rhythmics of accents which are bound with it, personify that general quality which enters into a fertile interrelation with the particular subjective element of a work of art, and by which it proves itself to be such. The symbiosis refers to all strata, from the smallest musical element to the total form. The general element participates in the same way to the construction of motif, phrase, theme and period as in the realisation of tone-space relations, which result from the unity of counterpoint and harmony. These react most sensitively to a disproportion of both categories. Thematic-motivic contexts are still feasible even in disappearing or completely absent tonality, but tone-space connections are no longer possible. They are the surest criterion for an understanding between the general and the particular.

The way the work can be bound to a tonal order as a general phenomenon by means of motivics as the particular in each case is illustrated in several examples from Beethoven's piano sonatas. The effectiveness of pivotal tones, which require motivics but which are not identical with them, becomes obvious. The anchoring of motivics in tonal space seems - when superficially considered - to impose restrictions on the composer, but in reality it allows him to link on an otherwise unattainable profusion of structural connections. Pivotal tones reveal the idea of a frame- 
work. This idea strives for a tonal realisation. It could be demonstrated by the principle of variation which is only possible because it conceals a theme behind its external appearance.

New music, however, is threatened by the loss of order in tonal space. This danger was recognised by Paul Hindemith, and Arnold Schoenberg tried to overcome it by means of dodecaphony. Yet all more recent systems of order have a character of particularity and approach arbitrariness and chance. The loss of a general element in our time is indisputably and obviously conditioned by a far-reaching displacement and suffocation of spiritual forces in the age of technology and manipulation, but the longing for this is as real as ever. On this rests the change of tradition and our love for Beethoven, which as yet has not been shattered by any kind of manipulation. 